John Carroll University

Carroll Collected

Sociology

2014

\title{
Deciding on leave: how US women in dual-earner couples decide on maternity leave length
}

Medora W. Barnes

John Carroll University, mbarnes@jcu.edu

Follow this and additional works at: http://collected.jcu.edu/soc-facpub

Part of the Family, Life Course, and Society Commons

\section{Recommended Citation}

Barnes, Medora W., "Deciding on leave: how US women in dual-earner couples decide on maternity leave length" (2014). Sociology. 28.

http://collected.jcu.edu/soc-facpub/28

This Article is brought to you for free and open access by Carroll Collected. It has been accepted for inclusion in Sociology by an authorized administrator of Carroll Collected. For more information, please contact connell@jcu.edu. 


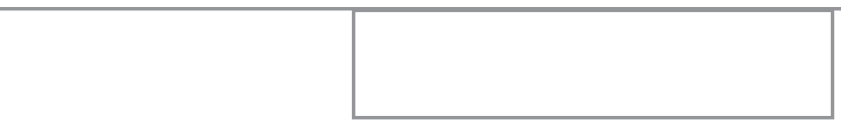

\title{
Deciding on leave: how US women in dual-earner couples decide on maternity leave length
}

\author{
Medora W. Barnes, John Carroll University, USA \\ mbarnes@jcu.edu
}

\begin{abstract}
This research contributes to the dialogue on maternity leave policy in the United States through analysing how pregnant school teachers with access to extended maternity leave decide how long a leave to take. The lived experiences of new mothers are examined through a series of longitudinal interviews with 16 public school teachers conducted at three points over the course of the transition to parenthood (pregnancy through first year). Findings indicate that although financial reasons played a large role in women deciding to return to work more quickly, issues of professional identity and personal happiness were also meaningful. Additionally, holding gendered parenting ideologies and being uncomfortable with available childcare options were important in the decision to take an extended leave.
\end{abstract}

key words maternity leave $\cdot$ transition to parenthood $\cdot$ motherhood $\cdot$ teachers

\section{Introduction}

In the last 20 years, the United States (US) has not passed any major federal initiatives to help workers integrate their work and family demands even though average work hours for employed Americans continue to increase - especially for dual-earner couples (Jacobs and Gerson, 2004; Coontz, 2013). The rates of children who live in homes where every adult works has also grown (Boushey and O'Leary, 2009), yet the types of robust policies that would allow parents to balance their responsibilities have not been enacted. Twenty years ago, the US passed the Family Medical Leave Act (FMLA) in 1993, which guaranteed 12 unpaid weeks of parental leave for those working full time. Although there were numerous restrictions, which allowed only half of US workers to be eligible for the leave, it was a start. As we mark the 20th anniversary of its passage, numerous scholars and policy experts have offered opinions about how to improve on the existing legislation.

The US is unique among developed nations in not offering any paid maternity leave and experts agree that the importance of leave being paid cannot be overstated (McGovern et al, 2000; Kamerman, 2006). Studies have found that at least partial wage replacement is essential in making it possible for women - especially low-income and single women - to be able to take even the minimum period of recommended leave (usually six weeks) for the last stage of pregnancy and looking after their newborn (Gerstel and McGonagle, 1998). Scholars and policy makers are not in consensus over how long an ideal maternity leave in the US would last. Many countries, including 
Canada, Japan and most of the European Union have policies in place that allow women to be on maternity leave with either full or partial wage replacement for one to three years. Whether a paid parental leave policy of this length would be appropriate (or feasible) in a US context is debatable. Although family leave policies increase women's attachment to paid work in the short term, long periods of supported leave can reduce job skills, suppress advancement and lead to greater gender wage gaps (Gornick, 2000). Similarly, policies that allow for part-time work may benefit mothers in the short term by increasing the flexibility in work options, but could create a 'golden ghetto' for women by offering a restricted choice of occupations and lowering average hourly wages (Gornick, 2000; Hartmann and Lovell, 2009).

This study is a qualitative analysis intended to help inform maternity leave policies within the US. It examines the lived experiences of new mothers who are part of a dual-earner couple to analyse how they decide on leave length when they have multiple options available through their employer. The factors that might lead a new mother to take (or forego) an extended leave are important pieces in this evolving national conversation.

\section{Explaining maternity leave length}

Although we know that utilisation of family/maternity leave is positively associated with factors such as mothers' continued employment, parental bonding and infant and maternal health (McGovern et al, 2000; Tanaka, 2005; Kamerman, 2006; Moss and O'Brien, 2006), one area that remains less studied is how women in the US who do have access to extended leave decide on maternity leave length. On the most basic level, previous research has found that when (or if) a woman decides to return to work following the birth of a child is strongly influenced by the amount of job-protected leave that is available to her (McGovern et al, 2000; Singley and Hynes, 2005).

The availability of paid leave, as opposed to unpaid leave, also increases the average length of leave that mothers take (Gerstel and McGonagle, 1998; McGovern et al, 2000; Kamerman, 2006). Additional financial factors are also associated with a woman's leaves. Spousal earnings have been found to have a sizable effect on maternity leave length, with those women whose husbands make more money taking a longer maternity leave (McGovern et al, 2000). In addition, women who pay more for childcare are more likely to take a longer leave (McGovern et al, 2000).

Another aspect thought to be an important influence is informal workplace culture, with those women who perceive their employers to be supportive taking more time off from work (Fried, 1998; McGovern et al, 2000). Other job-related characteristics also play a role, with those women who perceive their jobs to be 'flexible' and who report more 'work pressures' both taking less time off (McGovern et al, 2000).

Lastly, a few studies have found that a parent's gender ideology can influence the length of parental leave and the number of hours one works while one's children are very young (Kaufman and Uhlenberg, 2000). These elements are considered carefully in this study; as how gender and parenting beliefs shape work-family decisions is an important counterbalance to solely structural viewpoints. Issues of gender may become more salient for individuals during the transition to parenthood, as during this time noticeable gender differentiation often emerges in work and family patterns (Cowan and Cowan, 1992; Sanchez and Thomson, 1997). Previous research suggests that during this time, biological, cultural, interactional and institutional forces come 
together to provide a gendered influence on men's and women's work and family lives (Cowan and Cowan, 1992; Sanchez and Thomson, 1997; Walzer, 1998; Singley and Hynes, 2005).

\section{Theoretical background: lived experiences, gender strategies and parenting ideologies}

Qualitative methods were used in this study to draw out the complicated nature of women's work-family choices and their perceptions of them. To explore how each woman made decisions about maternity leave, attention was focused on the interaction between her lived experiences, gender ideologies, beliefs about parenthood and the structural limits imposed by her situation. The concept of 'lived experiences' is significant because it acknowledges that a person's life experiences and their perceptions of those life experiences are interdependent (Smith, 1987). Coming from a symbolic interactionist paradigm, a focus on lived experiences implies that the social world cannot be known objectively, but instead can only be understood through human interpretations and perceptions (Smith,1987). When addressing work and family decisions, an individual's perception of earlier events, such as their own parents' marital and work histories, may have a profound effect on how they choose to integrate work and family into their own lives.

One's gender ideologies can affect lived experiences by influencing both one's experiences and one's perception of those experiences. Gender ideologies are the set of beliefs that each individual has concerning the proper roles of men and women. Research has shown that people's employment aspirations appear to be shaped partly by what they believe is socially appropriate and feasible given their gender (Jacobs, 1989; England, 1992), although recent cohorts of young women are more likely to hold beliefs about the importance of career success that are similar to their male peers (Galinsky et al, 2009).

Gender is also an essential component of parenting expectations and roles, and how men and women feel about their assigned roles (Hochschild, 1989; Walzer, 1998; Garey, 1999). West and Zimmerman (1987: 126) have added to our general understanding of gender by describing it as something that we 'do', as a 'routine, methodical, and reoccurring accomplishment'. They, along with other scholars (see Berk, 1985; DeVault, 1991; Coltrane, 1996), have argued that one reason for the gendered division of household labour is because of the symbolic importance of doing household work in enacting the categories of 'masculine' and 'feminine'. Scholars have also argued that people 'do' motherhood and fatherhood in the same ways that people 'do' gender, in that they are defined by people through social interaction (Walzer, 1998; Garey, 1999).

Individuals' beliefs about parenthood may be more or less gendered.These parenting ideologies can vary based on whether the individual believes there are 'natural' or biological differences between mothers and fathers. While some women in this study saw mothering and fathering as equal roles, others clearly conceptualised mothers as the primary parent and fathers as secondary and connected it to biological explanations. They all attempted to make decisions that were consistent with their beliefs about the gendered nature of parenthood, in addition to specific practical limits (money, hours in the day etc) that they had to work within. Examining gendered parenting ideologies emphasises that families are integrated into broader systems 
of power, and also focuses on how cultural institutions are important in shaping appropriate parenting behaviour.

Through the decisions they made, the women in this study also attempted to enact their conceptualisation of the role of a 'good mother'. For many of them, this conceptualisation was influenced by what Hays (1996) has called the 'ideology of intensive mothering'. This is a gendered parenting ideology that says the mother is supposed to be the most important person in the child's world, regardless of the father's desires or level of participation. Intensive mothering is also seen as being child centred, emotionally absorbing, usually financially expensive, and labour intensive (Hays, 1996). As Hays (1996) points out, these sorts of practices and beliefs have been commonly depicted in the media and childrearing books for the last few decades as what 'good' mothers 'do', which make it difficult for mothers to resist the ideology.

\section{Methods}

\section{Procedure}

The data for this research were collected as part of a larger longitudinal study of how public school teachers negotiate work and family decisions during the transition to parenthood.A series of three in-depth interviews were conducted with 16 heterosexual married couples (16 men and 16 women) during the transition to parenthood. Eight couples were having their first child and eight were having their second child. Semistructured interviews occurred at three points in time: (1) during the final trimester of pregnancy, (2) 8-21 weeks after the baby's birth and (3) close to the baby's first birthday. As part of the larger study the husband and wife were each interviewed separately and then a joint interview was conducted, at each interview point. This resulted in a total of three interviews per interview point (and ideally nine interviews per couple). None of the couples dropped out during the study and the mothers were each interviewed at all three points. Minor deviations due to fathers being unavailable at either the second or third time point resulted in a total of 130 interviews.

The data for this article are drawn from the individual interviews conducted with the mothers mainly during the first and second interview points. Particularly pertinent topics included:

- their initial plans;

- how long a leave they took;

- why and when they made the decision;

- who was influential in the decision process;

- how they felt about their decision in retrospect.

Other topics included:

- why they decided to become a teacher;

- their marital history;

- their division of housework and childcare;

- their parents' marital and work histories;

- their expectations of (and later experiences with) motherhood. 
At each interview point, the individual interviews took approximately an hour and were audiotaped for later transcription. In addition, each participant completed a short demographic survey and a brief survey concerning the division of housework and childcare.

\section{A focus on teachers}

To locate public school teachers, participants were sent emails inviting them to take part in a study on balancing work and family responsibilities. The emails were sent to their publically available work emails with a request to forward the email to others who may fit the sample profile. Emails were sent to all teachers with female-sounding names in 48 schools $(\mathrm{K}-12)^{1}$ in three disparate counties in Connecticut. In addition, six women were recruited through snowball sampling methods, where participants were asked if they knew other pregnant teachers who would be interested in participating.

The decision to limit the occupational categories to only teachers was made to avoid variation in the type and length of family leave available, and because teachers are one of the only US occupations to have access to extended maternity leave. All of the women qualified for the 12 unpaid weeks available under the FMLA. In addition, they could take the first six weeks as paid weeks, as long as they had accrued an equal number of sick days within the system (this commonly took 18 months of teaching and all the participants had done so). Beyond this, each woman was also allowed to take off either the rest of the school term (September to January; January to June) or the rest of the school year in which she gave birth, before returning to her job. This type of 'extended' leave was unpaid but allowed the women to return to their same classroom at their same level of pay. Being able to take off almost a year of jobprotected leave from one's employment is rare within the US and makes this a key occupational group to study.

There are other reasons why teachers are a worthwhile occupational group on which to focus also. Of important theoretical concern is that teachers are not an elite group. Too often researchers interested in work-family decisions have focused on women with successful 'high-powered' careers in male-dominated fields or on those who work a great number of hours (Hochschild, 1997; Tichenor, 2005). Although women can be found in all lines of work, the majority of women still work in less elite female-dominated fields (Padavic and Reskin, 2002). When scholars choose to focus on elite women in male-dominated professions, they may be decreasing the relevance of their findings for the majority of women. By focusing on women in a non-elite female-dominated job, this study will serve to counterbalance some of the existing research on elite women and may pertain to women so far understudied. Additionally, while traditionally teaching has had a reputation for being 'family friendly', recent research has illustrated the long hours and dedication involved in this occupation and questioned this assumption (Drago, 2001). Furthermore, as there are over 2.5 million women in the US who work as primary or secondary teachers, they are also numerically a worthwhile group to study (National Center for Education Statistics, 2009a). 


\section{Participant characteristics}

One result of interviewing women who work in the same occupational position is that it minimised socioeconomic diversity within the sample, although the different occupational positions of the women's husbands add some variation. Five of the women were married to men who were also public school teachers, while the remaining 11 women had spouses who were employed in a range of occupations. These included scientist, technical writer, construction foreman, draftsman and selfemployed landscaper. The household incomes ranged from US $\$ 80,000$ to US $\$ 160,000$ per year, with a mean annual household income of approximately US $\$ 109,000$. The female participants earned a significant portion of the household income, with an average income of US $\$ 52,000$. In Connecticut, at the time of the interviews the mean household income was $\$ 96,502$ and the median was $\$ 69,243$ (U.S. Census Bureau 2012). In lay terms, all the participants lived in families that would be categorised as either middle or upper-middle class within their region of residence. There was a fairly wide range in the social class of their families of origin, from working-class to upper-middle-class backgrounds.

Fourteen of the 16 women in the study were white, while one participant was Hispanic and one bi-racial (White and Asian). This lack of racial diversity may have been influenced by the decision to focus on public school teachers, as this occupation is largely white. In 2008, approximately $83 \%$ of all US public school teachers were classified as non-Hispanic White, 7\% were non-Hispanic Black and 7\% were Hispanic (National Center for Education Statistics, 2009b). All the women interviewed were born between 1974 and 1979, putting them in their late twenties to early thirties at the time of their participation.

\section{Data analysis}

Like many other researchers who conduct semi-structured interviews, I relied loosely on grounded theory methods of data analysis. Grounded theory methods involve taking an open-ended approach to one's data and modifying hypotheses as the analysis proceeds (Glaser and Strauss, 1967). As part of the grounded theory technique, I used a thematic or 'issue-focused' approach to data analysis (Weiss, 1994). Due to the iterative nature of the data collection and analysis, my preliminary analysis informed and shaped subsequent interviews and analysis. After open coding for general topics and themes, I worked on looking for relationships between the codes, and collapsing and splitting the original coding categories. My final codes were developed and refined in ongoing interaction with the data and data collection process, until eventually the separate themes could be integrated into a single coherent story (Weiss, 1994). I also used NVivo qualitative software as an organisational tool in some portions of the coding process. Many authors doing research on work and family choose to use this type of thematic method of analysis (Hochschild, 1989, 1997; Walzer, 1998; Garey, 1999; Gerson, 2009).

Conducting longitudinal interviews had several advantages, including avoiding the bias that may exist in relying on only retrospective narratives and offering an opportunity to get corrective feedback on previously obtained information (Reinharz, 1992). Because this study used a non-random sample, it is not generalisable to any larger population; however, like most other qualitative studies, generalisability is not the 
major purpose of this research; instead, it focuses on describing in detail a particular process and experience (Krefting, 1999).

\section{Findings}

The women in this study made a variety of choices concerning how long a maternity leave to take. Their decisions were naturally clustered into three groups. The first group includes those women (four of 16) who took a shorter amount of leave and chose to return to work after six to 10 weeks. These women all took the six paid weeks of leave but chose to take less than the 12 total weeks available under the FMLA. The second group (nine of 16) took between 12 and 16 weeks off before returning to work. Mathematically, as well as in their own perception, they took an average amount of time off. The third group was composed of those women (three of 16) who chose to take an extended leave, as they took more weeks of leave than are available under the FMLA. All of them had their children during the school year and chose to return to work when the next school year began (at the end of August). One woman's child was born the first week in September, so she took off almost 12 months before returning. The other two women had their babies during the winter months and returned six or seven months after his or her birth.

\section{Reasons to return to work}

\section{The usual suspects: finances and workplace culture}

Two reasons that a considerable amount of previous research has found to affect the length of maternity leave are financial issues and concerns about employers' perceptions (Hochschild, 1997; Fried, 1998; Jacobs and Gerson, 2004). It was not surprisingly, then, that money appeared to influence the decisions of the women in this study. When discussing their return to work, all of the women in the study mentioned how important their own income was to their family. This reliance on the wife's income reflects the broader shift in the economy and in the structure of the family (Jacobs and Gerson, 2004). Although there was no correlation with their actual household income or whether they were making more or less money than their husbands, women who took a shorter- or average-length leave especially stressed that their incomes were necessary in maintaining the family's largely middle-class lifestyle, so this may be a matter of perception.

Although of all the women felt that their workplaces supported their decision to take the 12 weeks available to them under the FMLA, about a third of the women said that their administration would not be 'open' to a request for an extended leave and expressed concerns that taking one might have a negative effect on their longterm employment. This potential for negative consequences on parents has been described as 'hidden costs' in using work-family benefits (Jacobs and Gerson, 2004).

Unlike previous research on women in male-dominated fields who feel pressure to avoid taking a family leave due to the low usage rates by other company employees, the women in this study reported feeling pressure not to take an extended leave because so many female teachers recently had taken advantage of the extended leave policies: 
'Recently it's been very difficult in [Middletown] to stay out the whole year $\ldots$ at the time I was pregnant, I was one of 10 teachers in the district who was pregnant, and I think the district was spread thin. And they just weren't able to do it, so that if a person was going to stop teaching; they just needed to hire someone else.' (Audrey, sixth grade)

From the women's descriptions it appeared that in most instances the administration's attempt to limit extended leave appeared to be only through informal measures. Regardless, the negative attitudes of the administration decreased the desirability of taking an extended leave.

\title{
Role identity, self-concept and happiness
}

Although finances and employer support for family leave were important in the women's decisions about leave, the women also emphasised other aspects that made taking an extended leave undesirable. Many of the women reported that they had considered becoming a teacher from an early age and all of them emphasised the hard work that they put into becoming one. For many of these women, being an active teacher was a significant part of their understanding of who they were and maintaining their adult identity. Overall, two thirds of the women said that they loved their jobs and would miss teaching if they did not do it for an extended period:

\begin{abstract}
'When I was younger, I thought for the longest time that I would [take an extended leave] but I love teaching and I want to go back. We have a new math programme, and I'm so upset that I'm not going to be there to start the new school year with my new math programme. At the same time, I'm getting this baby - I know the math programme should be the last thing on my mind - but it just is. And I want to instil all my new ideas, so I'll be happy to go back to work.' (Audrey, fourth grade)
\end{abstract}

'[My husband's] mum was home with him and my mum was home with me. But at the same time, I always pictured myself working, at least half time. I don't want to lose that part of me.' (Heather, fourth grade)

In addition to missing teaching, some women said that they did not believe that they had the right personality to be a good stay-at-home mother for a period of several months, regardless of their choice of career. While identities are usually context specific and closely linked to social roles, a personality or self-concept is usually understood as a more generalised view that a person has of themselves (O'Brien, 2006). For these women, having a paid job to go to each day was essential to their view of themselves and their life satisfaction. They described not wanting to leave the labour force for the several months that an extended leave would entail. These explanations about personality and happiness were often intertwined with those about money:

'Part of the reason that [my leave] is not longer is because of financial reasons, but number two, I'm just not stay-at-home mum material. I need to get up, to shower ... I have a graduate degree! [Laughs] I need to know that I have that for a reason.' (Jennifer, kindergarten) 
Although the women sometimes sounded somewhat apologetic about their attitudes, they described returning to work as something that they wanted to do. Throughout their interviews they were consistent in explaining that, while they loved their children (or anticipated that they would), they enjoyed working and said they would be ready to return to work after several weeks off. Six women brought up this idea that they were not good stay-at-home mother 'material' in their descriptions of how they decided on their maternity leave length.

\section{Reasons for taking a longer or extended leave}

Although all of the women in this study returned to work less than 12 months after having a baby, they did discuss factors that made returning more difficult and/or encouraged them to take more time off. The two most common were:

- believing in gendered parenting ideologies that underscored the primacy of the mother-child bond;

- not feeling comfortable with the available childcare options.

\section{Gendered parenting ideologies}

One issue that impacted the length of leave that women preferred was how gendertyped their parenting ideologies were. I am using the term 'parenting ideologies' to refer to the ideas and ideals that an individual expresses about mothering and fathering. A person's parenting ideologies may be highly gendered or may reflect a belief in gender similarity. Holding gendered parenting ideologies should not be equated with holding a belief in traditional gender roles or norms in all realms of life. In fact, the couples who participated in this study all expressed a general belief in gender equality and (among all but one) egalitarian gender roles. This was frequently expressed through their statements that couples 'should' determine the division of housework based on what each person 'was good at' or enjoyed instead of on the person's gender. In one woman's words: "By no means do I think that just because I'm a girl, I have to do the laundry or the dishes. Or because he's a boy he has to mow the lawn. No, I don't think that way at all!" (Tara, first grade). These sorts of attitudes about gender equality also have been found within the larger population, as $72 \%$ of men and women between the ages of 18 and 29 recently reported that the best marriage would be one where both the husband and the wife take care of the house (Pew Research Center, 2010).

Yet, as many scholars have found, the belief in gender equality in housework does not always match the ideal (Gerson, 2009; Harrington et al,2011) and only about half of the women in this study succeeded at having divisions of housework pre-baby that appeared to be more or less equal in time and effort. Nonetheless, it is important to note that the majority of women who were in an unequal situation were unhappy with this situation and actively complained about it. Overall, it was clear that the participants believed that a wife had the right to try to get their husbands to do an equal amount of the housework, as they were both working full time outside the home. Although husbands could sometimes use their gender privilege to 'get out' of certain household tasks (most frequently laundry), these dual-earner women expected their spouses to be active participants in doing at least some of the traditionally female-typed tasks. 
In sharp distinction to the women's unanimously expressed belief that there was nothing inherent in being a man or a woman that meant you would be better at particular household tasks, almost half of the women (seven of 16) held clearly gendered parenting ideologies. Like many other types of dominant ideology, the belief that motherhood and fatherhood are gendered and unequal concepts was presented as 'natural' by the participants and frequently perceived as being connected to biological gender differences. The fact that the women would be recovering from childbirth, and that the women may be breastfeeding, were often mentioned as part of women's 'instinctual' or 'natural' bond that they had with the child. The fact that men could not breastfeed was regularly brought up to explain men's secondary role in parenting over the first year, even among women who breastfed for a very short period of time (a few days or weeks):

'I think there the gender might matter a little bit more [in parenting], because we're physically connected to these kids. It's like, they came from us. And even though the dad had a pretty big role in that, you carried this baby. And I think that you just automatically have the instincts to do certain things and want to do certain things. Sometimes you have to train yourself to let him do it.' (Sarah, high school special education)

In so far as these women believed that the mother 'should' take precedence over the division of babycare and felt that women were 'naturally' better at babycare tasks, they felt a greater tug to do more of the childcare tasks. This frequently led to the development of a 'manager-helper' dynamic between the mother and the father. The conceptualisation as the mother as the more important or 'more connected' parent also bolstered the women's attempts to live up to the cultural ideologies of intensive mothering. Therefore it is not surprising that those women who held strong gendered parenting ideologies also tended to feel guiltier at leaving their child with a paid caretaker and to have at least seriously considered taking an extended leave from work.

Among the nine women who did not express a strong belief in gendered parenting ideologies, there were a range of beliefs. Five women were ambivalent and unsure about how mothers and fathers should divide the care of their new babies. One woman explained, saying: "I don't know. I don't have an answer for that. With my husband, I feel that even with bathing [the baby], things like that don't come natural for him, and they do more so for me, but I can't say that about everyone" (Heather, fourth grade).

That these women were unsure about the connection between gender and parenting is also significant. Those men and women with unclear parenting ideologies may be likely to follow the ideologies of intensive motherhood because of the cultural dominance of this model. Only four of the 16 women were consistent in stating that mothers and fathers should have similar roles in childrearing (a clear rejection of gendered parenting ideologies). None of the women who held 'symmetrical' parental ideologies took an extended family leave. Not coincidentally, these women also tended to have a more equal and less gendered division of domestic labour in their families both before and after having children. 


\section{Comfort level and availability of childcare}

When discussing how long a maternity leave to take, one of the underlying issues was the woman's views on paid childcare and her comfort level with her specific childcare arrangements. Almost all of the first-time mothers discussed having to engage in emotion work or 'convince themselves' that there was nothing wrong with putting an infant in paid childcare. One woman explained what she based her decision on when she returned to work after only nine weeks:

'It was the money, and it was talking to friends and calming myself down that I really could send an eight-week-old or nine-week-old baby to daycare. I had to get rid of that fear - that was even more important than the money. My friends really did help me with that.' (Lauren, high school physical education)

A strategy that women used to feel more comfortable with their childcare arrangements was to rely on family members - most frequently the woman's mother. Of the 16 women in this study, five of them were using parents to help with childcare during the first year, at least a few days of the week. The financial advantage of these arrangements was not emphasised as much as the superiority of the care that the child would be receiving. This lack of emphasis on finances may reflect the secure class location that the participants found themselves in. Although they all complained that childcare was very expensive, they all were to some extent capable of paying for it. Four of the women had their own or their husband's mother watching the baby either two or three days a week and were using paid childcare the other two or three days, while one woman's mother was watching her baby full time. This latter woman and her husband were very happy with this arrangement. When the woman was asked how she decided when to go back to work, the first item she mentioned was childcare.

'Once my mom said that she would watch the baby full time, I felt like, "Okay, then." [Gives an exaggerated sigh] She has watched a lot of my other nieces and nephews as well. That was a relief for me. Then I felt like, "Okay, the child's not just going to a stranger." (Rita, fifth grade)

While Rita and the other women utilising family help admitted that there were some disadvantages to using family members such as having to be sensitive with criticisms and directives, in general they were happy to have parents who could help. Although research has found that using family members for childcare is often unsatisfactory (Uttal, 2002), the contentment these mothers showed may be due to how young their children were (less than a year), their own and their parent's class position (largely middle class), and that they saw it as a temporary arrangement that would not last more than a year or two.

Having a family member who was able to help with childcare, even part time, appeared to discourage women from requesting to take an extended leave. None of the five women utilising family members for care decided to take any leave beyond the FMLA weeks. In addition, all three of the women who did take an extended leave mentioned that they did not have any relatives who would have been able to help with childcare during or after the mother's maternity leave. The childcare system in the US has been described as working on a 'mother substitute' model (Clawson and 
Gerstel, 2007). For these women, literally having their mother or mother-in-law able to act as their substitute when their child was very young seemed to be reassuring. As Rita articulated above, the concern about having a baby watched by 'a stranger' was very scary for many of the women who worried that the childcare centres were not caring environments or of high-enough quality due to the lack of good monitoring methods in the US childcare system.

Except for one woman who was able to split the costs with a relative to have a nanny come to their house, all the rest of the women in this study chose at-home daycare for their children rather than daycare centres.

'We're using a home daycare. I think a home daycare is a lot more personable. They're not just caught in the shuffle of things. They're not a paycheck. Some daycare centres are great, but I've worked at a bunch of daycares and I know how they run, so I love the idea of a home daycare.' (Tara, first grade)

The women tended to emphasise the 'home' nature of the daycare they chose and how wonderful the woman running the daycare was (none was run by men). As public school teachers in the community, quite a few of the women knew the biological children of the daycare provider or knew children that the provider had watched previously. Julie, pregnant with her second child, explained:

[Asked: What kind of childcare are you planning to use?] 'There's a home daycare, and she is awesome. I really like her a lot. Her kids actually go to the high school, and you can kind of see how they turned out as human beings, and they're awesome. Her husband's a police officer, and they're really - it's like a family there, so I don't feel as bad.' (Julie, high school history)

In this statement, Julie calls on several themes:

- that the provider is "awesome";

- that she can look at the provider's children to judge the parenting skills of the provider;

- that the daycare is "like a family", which helps her not feel "as bad" about having a baby in childcare.

This idea that her child would be spending time in a "family" rather than in a less personal centre was very appealing to the women and helped to ease anxieties over using paid childcare.

As the largest percentage of children in the US who are in paid childcare are at daycare centres (Clawson and Gerstel, 2007), the fact that none of the couples in this study used a centre was quite noticeable. Over half of the women had worked at a daycare centre at some point before they became a teacher and they consistently said they did not want their baby in that type of environment. Although I am unaware of any statistics that examine how having a woman work in a daycare centre influences her subsequent childcare decisions, my data suggest that the experience discourages people from utilising centres with their own children (at least while they are under a year old). Other reasons why these women might have chosen home daycare is that they were frequently less expensive than daycare centres and were more often run 
on a public school schedule, which made them highly compatible with the women's work schedule.

\section{Discussion}

Coontz (2013: SR1) recently wrote in The New York Times:

Today the main barriers to further progress toward gender equity no longer lie in people's personal attitudes and relationships. Instead, structural impediments prevent people from acting on their egalitarian values, forcing men and women into personal accommodations and rationalisations that do not reflect their preferences.

Here she is drawing attention to the structural barriers that continue to exist in the US, which prevent women and men from being able to easily or happily combine parenthood and working life. Certainly one of these impediments is the lack of a maternity leave that is paid, which makes things more difficult for every new working mother and her family.

The women in this study felt that their incomes were important to their family. Some chose to take very short leave, and the financial impact was one of the main causes. A paid maternity leave (beyond six weeks) would have been an asset to all of them. Yet most of the women also really cared about their jobs and felt that being a teacher was an important part of their identity. Across the nation, young women's attitudes about the importance of career success are increasingly matching that of men's (Galinsky et al, 2009). Having relatively short maternity leaves that are paid is known to increase women's attachment to the labour force and allow them avoid unnecessarily leaving the labour force (Gornick, 2000).

On the other hand, in contrast to part of Coontz's statement, there were signs within this study that women's parenting relationships were not always characterised by egalitarian values. Those women who did desire an extended family leave were influenced by gendered parenting ideologies, which were noticeable for their contrast with their otherwise expressed beliefs in gender egalitarianism. Although it has been theorised that couples often 'do' gender-typed housework tasks as a way of 'doing gender' in the husband/wife role (Berk, 1985; West and Zimmerman, 1987; Coltrane, 1996), the participants in this study seemed to feel less need to use housework in this manner, perhaps due to their relative youth. Nonetheless, the majority of the women were still clearly gendered in the ways that they were 'doing' parenthood (Walzer, 1998; Garey, 1999). This does not mean that improving maternity leave policies would not help them to balance their work and family responsibilities - it just means that structural obstacles are not the only thing still stopping the US from achieving gender equality in the home.

Among the women in this study, many tried to manipulate their schedules so that they could stay home with their baby for the first four or sometimes five months, although most chose to go back to work after that. Those scholars who study the statistical correlations between the length of paid parental leave and gender equality have hypothesised that the relationship may be shaped like an inverted ' $U$ ' (Hartmann and Lovell, 2009). Offering some paid leave likely would increase gender equality by strengthening women's attachment to their jobs and labour force participation but 
offering more than approximately six months of paid leave would begin to reduce gender equality in the US by encouraging women to take extended breaks from employment (Hartmann and Lovell, 2009). The present qualitative analysis suggests that many middle-class women - or at least teachers and those working in similar fields - would find this recommended six months of paid leave to be an appropriate amount of time to spend with their new babies, and would prefer not to stay out a year or more, as mothers do in many European countries. Six months would allow the new mothers the chance to bond with their babies and keep their baby in their home for the first few months. It is also short enough that it would allow them to maintain their professional identities and avoid increased pressure to stay at home against their wishes, as longer leaves might do.

Any upcoming revisions to US family leave policies will need to allow enough flexibility to meet the increasing variation in family form to be effective. It will also need to be accompanied by improvements in the childcare system, as childcare for young children and the availability of parental leave are not issues that can be effectively dealt with separately. Many of the women in this study worried about the quality of childcare that was available to them and the cost of it. Similarly, paid sick and family care days are issues that continue to affect many parents and others in their caregiving responsibilities (Hartmann and Lovell, 2009).

This qualitative analysis is just one piece of a much larger policy puzzle. Very few women in the US currently have access to extended leave and examining their decisions is worthwhile. As all of the women in this study were largely middle class, white, heterosexual and working in the same occupation, these issues should be explored further with a more diverse sample. Hopefully, revisions to US family leave policies can gain momentum within the not so distant future.

\section{Note}

${ }^{1}$ In the United States children generally start public school at age five by attending kindergarten ('K'). Assuming adequate progress, they attend first grade the following year and advance to the next numeric grade each year after. Not all school systems break up the grades into schools in the same ways, although general, 9th-12th grade is high school, which students need to complete before they can apply to a university. Kindergartens through 4th-6th grades are generally grouped together in elementary schools. Middle schools (or 'junior highs') always include 7th and 8th grades and sometimes also include 5 th and 6th grades. Before kindergarten, a variety of preschools are available, although parents have to pay privately for them so not every child attends and there is great variety in the types of programs

\section{References}

Berk, S, 1985, The gender factory: The apportionment of work in American households, New York, NY: Plenum Press

Boushey, H, O’Leary, A, 2009, Executive summary, in H Boushey, A O'Leary (eds) The Shriver report: A woman's nation changes everything, Washington, DC: Center for American Progress

Clawson, D, Gerstel, N, 2007, Caring for our young: child care in Europe and in the United States, in S Ferguson (ed) Shifting the center: Understanding contemporary families, Boston, MA: McGraw-Hill 
Coltrane, S, 1996, Family man: Fatherhood, housework and gender equity, New York, NY: Oxford University Press

Coontz, S, 2013, Why gender equality stalled, New York Times, 17 February, SR1

Cowan, P, Cowan, CP, 1992, When partners become parents: The big life change for couples, New York, NY: Basic Books

Drago, R, 2001, Time on the job and time with their kids: cultures of teaching and parenthood in the US, Feminist Economics 7, 3, 1-31

Fried, M, 1998, Taking time: Parental leave policy and corporate culture, Philadelphia, PA: Temple University Press

Galinsky, E, Aumann, K, Bond, J, 2009, The national study of the changing workforce:Times are changing: Gender and generation at work and at home, New York, NY: Families and Work Institute

Garey,AI, 1999, Weaving work and motherhood, Philadelphia, PA:Temple University Press

Gerson, K, 2009, The unfinished revolution: How a new generation is reshaping family, work, and gender in America, New York, NY: Oxford University Press

Gerstel, N, McGonagle, K, 1998, Taking time off: job leaves, the Family and Medical Leave Act, and gender, in Women's progress: Perspectives on the past, blueprint for the future: Conference proceedings, Washington, DC: Institute for Women's Policy Research

Glaser, B, Strauss, A, 1967, The discovery of grounded theory, Chicago, IL: Aldine

Gornick, J, 2000, Family policy and mothers' employment: cross-national variations, in T Boje, A Leira (eds) Gender, welfare state and the market, London: Routledge

Harrington, B, Deusen, F, Humberd, B, 2011, The new dad: Caring, committed, and conflicted, Boston, MA: Boston College Center for Work \& Family

Hartmann, H, Lovell, V, 2009, A US model of universal sickness and family leave, in J Gornick, N Meyers (eds) Gender equality: Transforming family divisions of labor, London:Verso

Hays, S, 1996, The cultural contradictions of motherhood, New Haven, CT:Yale University Press

Hochschild, A, 1997, The time bind: When work becomes home and home becomes work, New York, NY: Metropolitan Books

Hochschild, A, 1989, The second shift, New York, NY: Avon

Jacobs, J, Gerson, K, 2004, The time divide:Work, family, and gender inequality, Cambridge, MA: Harvard University Press

Kamerman, S, 2006, Parental leave policies: the impact on child well-being, in P Moss, M O'Brien (eds) International review of leave policies and related research, London: Department of Trade and Industry

Kaufman, G, Uhlenberg, P, 2000, The influence of parenthood on the work effort of married men and women, Social Forces 78, 931-47

Krefting, L, 1999, Rigor in qualitative research: the assessment of trustworthiness, in A Milinki (ed) Cases in qualitative research: Research reports for discussion and evaluation, Los Angeles, CA: Pyrczak Publishing

McGovern, P, Dowd, B, Gjerdingen, D, Moscovice, I, Kochevar, L, Murphy, S, 2000, The determinants of time off work after childbirth, Journal of Health Politics, Policy and Law 25, 527-64

Moss, P, O’Brien, M, 2006, International review of leave policies and related research: Employment Relations Research Series No. 57, London: Department of Trade and Industry 
National Center for Education Statistics, 2009a, Digest of education statistics (NCES 2006-005), Washington, DC: Department of Education

National Center for Education Statistics, 2009b, Characteristics of public, private, and bureau of Indian education elementary and secondary school teachers in the United States: Results from the 2007-08 Schools and Staffing Survey (NCES 2009-324), Washington, DC: Department of Education

O'Brien, J, 2006, The production of reality (4th edn), Thousand Oaks, CA: Pine Forge Press

Padavic, I, Reskin, B, 2002, Women and men at work, Thousand Oaks, CA: Pine Forge Press

Pew Research Center, 2010, The decline of marriage and rise of new families, Washington, DC: Pew Research Center

Reinharz, S, 1992, Feminist methods in social research, New York, NY: Oxford University Press

Sanchez, L, Thomson E, 1997, Becoming mothers and fathers: parenthood, gender, and the division of labor, Gender \& Society 11, 6, 747-72

Singley, S, Hynes, K, 2005, Transitions to parenthood: work-family policies, gender, and the couple context, Gender \& Society 19, 3, 376-97

Smith, D, 1987, The everyday world as problematic, Boston, MA: Northeastern University Press

Tanaka, S, 2005, Parental leave and child health across OECD countries, The Economic Journal 115, 7-28

Tichenor, V, 2005, Earning more and getting less: Why successful wives can't buy equality, New Brunswick, NJ: Rutgers University Press

U.S. Census Bureau, 2012, Selected economic characteristics: 2007-2011 American Community Survey 5-Year Estimates, Retrieved on 11/5/13, http://factfinder2. census.gov/faces/tableservices/jsf/pages/productview.xhtml?src $=\mathrm{bkmk}$

Uttal, L, 2002, Making care work: Employed mothers in the new childcare market, New Brunswick, NJ: Rutgers University Press

Walzer, S, 1998, Thinking about the baby: Gender and transitions into parenthood, Philadelphia, PA:Temple University Press

Weiss, R, 1994, Learning from strangers: The art and method of qualitative interview studies, New York, NY:The Free Press

West, C, Zimmerman D, 1987, Doing gender, Gender \& Society 1, 2, 125-51 